\title{
Una reflexión general sobre las áreas metropolitanas*
}

\author{
José Luis Carro Fernández-Valmayor \\ Catedrático de Derecho Administrativo \\ Universidad de Santiago de Compostela
}

\begin{abstract}
Sumario: I. CONSIDERACIONES PRELIMINARES: EL RESURGIMIENTO DEL DEBATE SOBRE LAS ÁREAS METROPOLITANAS Y LAS DIFICULTADES DE LAS RESPUESTAS INSTITUCIONALES. II. LÍNEAS GENERALES DE LA EVOLUCIÓN DEL TRATAMIENTO LEGISLATIVO DEL FENÓMENO METROPOLITANO EN ESPAÑA. REGULACIÓN DEL FENÓMENO METROPOLITANO EN LA ETAPA CONSTITUCIONAL. III. LAS ÁREAS METROPOLITANAS EN LA LEGISLACIÓN BÁSICA ESTATAL. IV. LAS COMPETENCIAS METROPOLITANAS. La posibilidad de una cláusula general competencial. Carácter propio de las competencias. Ámbito competencial metropolitano y autonomía municipal. Una descripción general del ámbito competencial metropolitano. Una cuestión importante: ámbito competencial provincial y territorio metropolitano.
\end{abstract}

\section{CONSIDERACIONES PRELIMINARES: EL RESURGI- MIENTO DEL DEBATE SOBRE LAS ÁREAS METROPO- LITANAS Y LAS DIFICULTADES DE LAS RESPUESTAS INSTITUCIONALES}

En las páginas que siguen se trata de llevar a cabo una reflexión general sobre un tema, por lo demás, tan extenso, como el de las Áreas Metropolitanas, que, en los últimos tiempos, ha vuelto a suscitar un interés generalizado. En la medida en que estamos ante un tema que es susceptible de variados enfoques, todos ellos absolutamente necesarios, he de advertir, sin embargo, que el aquí adoptado es el enfoque jurídico, referido, más concretamente, al Ordenamiento local español.

El resurgimiento del debate sobre las Áreas Metropolitanas obedece a una serie de circunstancias, unas de carácter más permanente y otras de índole más coyuntural. Entre las primeras está, naturalmente, la persistencia en el tiempo del fenómeno de concentración de la población en torno a las grandes ciudades, que ha dado lugar a la constitución, por encima de los límites

\footnotetext{
"Ponencia presentada a las Jornadas Internacionales sobre "Las conurbaciones gallegas desde una perspectiva comparada", organizadas por la Consellería de Presidencia de la Xunta de Galicia y la Escola Galega de Administración Pública, con la colaboración de la OCDE, los días 30 y 31 de marzo de 2006 en Santiago de Compostela. Al texto, que se publica sin modificaciones, se le han añadido las imprescindibles notas bibliográficas y un sumario explicativo. La temática forma parte, por lo demás, de los Proyectos de investigación BJU2003-01752 y PGIDIT03CS020203, financiados por el Ministerio de Ciencia y Tecnología y la Xunta de Galicia.
} 
municipales, de espacios metropolitanos interrelacionados, con evidentes necesidades de planificación de infraestructuras y de conveniencia de prestación de servicios a ese nivel. Es innegable que la concentración urbana ha producido un evidente desarrollo económico, pero, a la vez, también es claro que ha planteado importantes problemas sociales (ligados a la noción de «peri-urbanización»), que exigen una adecuada respuesta institucional ${ }^{1}$. De otro lado, la idea misma de un desarrollo territorial, policéntrico y equilibrado, en el sentido, por lo demás, de la llamada Estrategia Territorial Europea ${ }^{2}$, con innegable vinculación al fenómeno de la globalización de la economía, contribuye, decisivamente, a fomentar el debate sobre la organización de los espacios metropolitanos ${ }^{3}$.

Las respuestas institucionales al fenómeno metropolitano han sido siempre muy variadas, pues no existe una única y definitiva fórmula organizativa ante los problemas que tal fenómeno plantea, tanto en materia de ordenación del territorio como en materia prestacional. Puede decirse, en todo caso, que dichas respuestas institucionales han venido revistiendo, en general, dos modalidades. Una primera, vinculada al hecho asociativo, mediante la constitución de mancomunidades o consorcios o la realización de convenios metropolitanos, y una segunda, dirigida a la creación de una específica Entidad local, con carácter monofuncional o plurifuncional ${ }^{4}$.

La opción por cualquiera de las citadas respuestas institucionales se ha encontrado siempre con una serie de dificultades específicas. Las fórmulas asociativas o convencionales, vinculadas a concretas finalidades, han manifestado cierta insuficiencia ante la generalidad de los problemas planteados en los espacios metropolitanos, produciéndose, en muchos casos, una creciente desnaturalización de dichas fórmulas a través de lo que plásticamente se ha denominado su «estiramiento competencial» ${ }^{5}$. La creación de una específica Entidad local se ha encontrado también, por su parte, con algunos obstácu-

\footnotetext{
${ }^{1}$ Vid. J. M. RodríGueZ Álvarez, «Las áreas metropolitanas en Europa: un análisis causal y tipológico», REALA, 298-299, 2005, p. 234.

${ }^{2}$ Cfr. sobre esta temática la importante y completa monografía de Teresa Parejo NAvajas, La Estrategia Territorial Europea, Universidad Carlos III-M. Pons, Madrid-Barcelona, 2004, en especial su capítulo III.

${ }^{3}$ Vid. E. ORduña Prada, «Las áreas metropolitanas», en La intermunicipalidad en España, Ministerio de Administraciones Públicas, Madrid, 2005, p. 96.

${ }^{4}$ Cfr. Ma C. Barrero Rodríguez, «La ordenación del territorio en los espacios metropolitanos», RVAP, 45-I, 1996, pp. 10-13. ORduÑa Prada, cit., p. 95.

${ }^{5}$ Vid. las reflexiones de $\mathrm{M}^{\mathrm{a}} \mathrm{C}$. BARRERo RodríGUEZ, «El juego de las Entidades supramunicipales en España. Algunas reflexiones en el décimo aniversario de la Ley de Régimen Local de 2 de abril de 1985». REALA, 264, 1994, pp. 650-651, 653 (aquí la expresión «estiramiento legal» de la figura de la mancomunidad) y 666. A. FANLO LORAS, «Estructura territorial», en Anuario del Gobierno Local, 1996, pp. 241 y 257-258. La necesidad de realzar la fórmula convencional en A. Pérez MoReno, «Las áreas metropolitanas entre la esperanza y la aporía», Revista de Derecho Urbanístico 1994, p. 949. Por la fórmula mancomunada y consorcial optó la Ley 7/1993, de 27 de julio, reguladora de la demarcación municipal de Andalucía.
} 
los importantes. El primero de todos ellos ha sido la ausencia de un modelo organizativo único de Área Metropolitana y de espacios metropolitanos uniformes. El segundo tiene que ver con la incidencia que la creación de cualquier tipo de Área Metropolitana ha supuesto para la articulación territorial de la correspondiente Comunidad Autónoma. El tercer obstáculo, en fin, lo ha constituido la permanente presencia de factores de signo político, incluso identitarios, en los procesos de creación de Áreas Metropolitanas como Entidades locales, dotadas de un importante acervo competencial y de una organización de cierta complejidad.

Puede decirse que, entre todas las figuras que conoce el Ordenamiento local, las Áreas Metropolitanas en concreto han tenido, por así decir, un destino paradójico. Por un lado, parece claro que el desarrollo de políticas públicas metropolitanas debe exigir, para ser eficaz, la existencia de un Ente u organización personificada que sea también un interlocutor institucional de las restantes organizaciones actuantes sobre el territorio y de los actores económicos y sociales, pero, por otro lado, y a pesar de esta necesidad, la creación de Entes Metropolitanos non ha conseguido, hasta el momento, consolidarse por razones fundamentalmente políticas.

\section{LÍNEAS GENERALES DE LA EVOLUCIÓN DEL TRATA- MIENTO LEGISLATIVO DEL FENÓMENO METROPO- LITANO EN ESPAÑA. REGULACIÓN DEL FENÓMENO METROPOLITANO EN LA ETAPA CONSTITUCIONAL}

Puede ser oportuno, para tener una visión global de los problemas que afectan a la organización del espacio metropolitano, que me refiera ahora, con trazos, naturalmente, muy gruesos, a la evolución que dicha organización ha experimentado en nuestro país. Evolución que, en líneas generales, puede venir caracterizada por dos notas principales: predominio excesivo de la ciudad central en la configuración del Área Metropolitana y esquema organizativo abiertamente centralista, basado en la creación de un organismo autónomo estatal. Notas que han colaborado, de forma decisiva, a una cierta mala imagen de las Áreas en el pasadó.

Suelen distinguirse, en nuestro país, distintas etapas en el tratamiento legislativo del fenómeno metropolitano, comprendiendo dentro de él también al más específico de las grandes ciudades como tales ${ }^{7}$.

\footnotetext{
${ }^{6}$ Vid. F. Sosa Wagner, Manual de Derecho Local, 9a ed., Thomson-Aranzadi, Pamplona, 2005, p. 135, donde alude a la mala imagen que las Áreas han proyectado como consecuencia de su inadecuado diseño en el pasado. Cfr. también $\mathrm{M}^{\mathrm{a}}$ C. BArrero Rodríguez, Las Áreas Metropolitanas, Instituto García Oviedo-Civitas, Madrid, 1993, p. 37.

7 Vid. la evolución descrita en M M $^{\mathrm{a}}$ C. BARRERo RodríGueZ, «Las Áreas Metropolitanas», cit. pp. 38 y ss. J. M. RodrígueZ ÁlvareZ, «La política sobre grandes ciudades y áreas metropolitanas en España o
} 
Precisamente, en la primera etapa, que se inicia en la inmediata posguerra, la gran ciudad era la protagonista por los problemas de desarrollo urbanístico que planteaba y a los que una serie de leyes (las llamadas «Leyes de grandes ciudades») intentaron encontrar una solución. En efecto, la finalidad de la Ley de 25 de noviembre de 1944 (desarrollada por Decreto de 1 de marzo de 1946) sobre la ordenación urbana de Madrid era, estrictamente, una finalidad urbanística, la de llevar a cabo el Plan General de Ordenación, para lo cual se creaban una serie de órganos con clara vinculación estatal (Comisión de Ordenación Urbana, estructurada por un Comisario General, dependiente de la Administración del Estado, asistido por una Comisión de Urbanismo, con amplia representación estatal). Al servicio de la finalidad urbanística se favorecía la aplicación decidida de la técnica de la anexión de municipios limítrofes. No existía, pues, una consideración global o conjunta del fenómeno metropolitano sino, simplemente, y con decisiva intervención estatal, la ordenación urbanística de la ciudad central, que iba extendiéndose merced al avance de los procesos de anexión ${ }^{8}$. Lo mismo puede decirse de los casos de Bilbao (creación de la Corporación Administrativa "Gran Bilbao" por Ley de 17 de julio de 1945) y de Valencia (creación de la Corporación Administrativa «Gran Valencia» por Ley de 18 de diciembre de 1946). El caso de Barcelona fue un poco distinto; la Ley de 3 de diciembre de 1953 creó la Comisión de Urbanismo de Barcelona como organismo autónomo dependiente de la Administración de Estado, aunque con participación local, a la que se encomendó, además del desarrollo del Plan Comarcal, el establecimiento de servicios públicos de interés municipal. Al mismo tiempo, como se advertía en la Exposición de Motivos de la citada ley, se abandonaba el esquema anexionista que había venido siendo aplicado hasta entonces. Esta primera etapa finaliza con la publicación de la Ley del Suelo de 12 de mayo de 1956, en donde se soslaya completamente el tema metropolitano.

La segunda etapa en el tratamiento del fenómeno metropolitano viene caracterizada por la aparición de una regulación especial para los municipios de Madrid y Barcelona, la cual, por cierto, no se extendía a toda la zona de influencia articulada en torno a dichas ciudades. En todo caso, a través de estas

\footnotetext{
el temor a la diversidad», en GAPP, 24, 2002, pp. 111 y ss. M. BASsols COMA, «La Administración de las grandes ciudades en España», en Organización territorial del Estado (Administración Local), vol. I., D.G. de lo Contencioso del Estado-Instituto de Estudios Fiscales, Madrid, 1985, pp. 595 y ss.; «La organización de las Áreas metropolitanas», en El Espacio Metropolitano, Temas de Administración Local núm. 30, INAP-CEMCI, Granada, 1989, pp. 47 y ss., en concreto, pp. 48-65. E. ARgulLol MurGADAS, «Las Entidades Metropolitanas», en Organización territorial del Estado, cit., vol. I, pp. 524 y ss. Ya antes, y de forma más minuciosa, vid. la descripción de las distintas etapas de la evolución normativa en Tomás-Ramón FernándeZ, «Áreas Metropolitanas y descentralización», en S. MARTín-ReTORTILLO, Descentralización administrativa y organización política, tomo III, Alfaguara, Madrid, 1973, pp. 651 y ss.
}

${ }^{8}$ En el Preámbulo de la citada Ley de Madrid se ordenaba al Ayuntamiento que formulase «propuesta de anexión total o parcial de los términos municipales colindantes...». Señala RodríGuEz Álvarez, La política, cit., p. 111, que entre 1948 y 1954 se produjo la anexión de 13 municipios vecinos, pasando el término municipal de la capital de $68 \mathrm{~km}$. cuadrados a 607 . 
específicas regulaciones, se pretendía superar el esquema rígidamente uniformista que había caracterizado hasta entonces al Ordenamiento local español. En efecto, la Ley de 7 de noviembre de $1957^{9}$ autorizó al Gobierno para establecer un régimen especial para los municipios de Madrid y Barcelona, autorización que se plasmó en los textos articulados aprobados, respectivamente, por los Decretos de 11 de julio de 1963 y 23 de mayo de 1960. Esta normativa, caracterizada, en términos generales, por un reforzamiento del Ejecutivo local (Alcalde y Delegados de Servicios) y la puesta en marcha de una cierta desconcentración local (Juntas de Distrito), no abordó, sin embargo, de manera directa, la problemática metropolitana. En todo caso, y ello fue oportunamente advertido en su momento ${ }^{10}$, la previsión de un régimen especial para las dos grandes metrópolis españolas manifestaba, claramente, que no nos hallábamos ante un simple problema de técnica urbanística, sino también, y sobre todo, ante una cuestión de gobierno ciudadano, que por su peculiaridad exigía instituciones específicas. En este sentido, no deja de ser significativo que la Ley Especial de Barcelona de 1960, forzando, por lo demás, el ámbito de la citada delegación legislativa, ampliase el ámbito funcional de su Comisión de Urbanismo para incluir también la gestión de servicios públicos comunes.

La previsión de una regulación especial para los municipios de Madrid y Barcelona no podía pasar por alto la innegable existencia de un importante espacio metropolitano alrededor de estas ciudades y es así como, para hacer frente a esta realidad, se promulgó inmediatamente la Ley de 2 de diciembre de 1963 sobre el Área Metropolitana de Madrid ${ }^{11}$, con la que se abre la tercera etapa de la paulatina aproximación legislativa al fenómeno metropolitano. Esta aproximación, sin embargo, continuaba siendo de carácter exclusivamente urbanístico. Se preveía la formulación de un Plan General de Urbanismo para todo el ámbito territorial del Área y se creaba, como órgano de coordinación y con naturaleza de organismo autónomo estatal, la Comisión de Planeamiento y Coordinación del Área Metropolitana (COPLACO). En el seno del municipio de Madrid se creaba también la Gerencia de Urbanismo, como organismo autónomo municipal encargado de la gestión urbanística que, incluso, previo acuerdo con la COPLACO podía actuar fuera de su término municipal. En todo caso, nada nuevo en el tratamiento del fenómeno metropolitano que continuaba siendo visto, como se acaba de apuntar, como un problema estrictamente urbanístico. Interesa, sin embargo, destacar, por lo novedoso, el Informe de la Comisión redactora del Anteproyecto de

\footnotetext{
9 Señala Rodríguez Álvarez, cit., p. 112, que la Ley de 1957 es «la primera norma en la historia del Derecho local español que supera el uniformismo municipal en el aspecto formal». También TomásRamón FERNÁNDEZ, cit., p. 659.

10 Tomás-Ramón FERnÁndeZ, op. y loc. cit.

${ }^{11}$ El Área Metropolitana de Madrid abarcaba inicialmente la capital y 22 municipios limítrofes, con una superficie de 1706 km. cuadrados. RodrígueZ ÁlvareZ, cit., p. 112.
} 
la citada Ley ${ }^{12}$, en donde se afirmaba ya la necesidad de un tratamiento global de la problemática de los espacios metropolitanos, con resuelta superación del sistema de anexiones y del establecimiento de una organización específica para toda el Área dotada de competencias generales. Pero lo que era particularmente importante de este Informe era su propuesta de sustitución de la provincia por el Área en el territorio metropolitano y ello por la sencilla razón de que "los problemas que surgen de una gran metrópoli alcanzan un índice de concentración tal, que justifican sobradamente unificar en su ámbito toda la actuación local posible". Esta propuesta fue, sin embargo, rechazada y, sin explicación de los motivos, no fue acogida en el posterior Proyecto de $\mathrm{Ley}^{13}$.

El caso de Barcelona fue algo distinto al de Madrid. El Decreto-Ley 5/ 1974, de 24 de agosto, creaba la Entidad Municipal Metropolitana de Barcelona como Entidad local, atribuyéndole competencias, no solamente en el campo urbanístico (ejecución del Plan Director Metropolitano), sino también en materia de prestación de servicios de interés metropolitano.

De esta etapa queda por reseñar que la Ley 41/1975, de 19 de noviembre, de Bases del Estatuto de Régimen Local, había previsto (Base 9a) las allí denominadas Entidades Municipales Metropolitanas con un ámbito de actuación, no solo urbanístico, sino también prestacional y con un órgano de gobierno denominado Consejo Metropolitano, cuyos miembros serían elegidos por cada uno de los Ayuntamientos afectados y por la Diputación Provincial. Esta Ley, sin embargo, no llegó a aplicarse, siendo expresamente derogada por la Ley 47/1978, de 7 de octubre.

Salvo la referencia a la posibilidad de creación en los Estatutos de Autonomía de circunscripciones territoriales propias o agrupaciones municipales distintas de la provincia (artículos 141-3 $3^{\circ}$ y $152-3^{\circ} \mathrm{CE}$ ), la Constitución española de 1978 (CE), centrada, sobre todo, en el reconocimiento y realce de la autonomía municipal emergente, no abordó, directamente, el tema de las Áreas Metropolitanas o el de los grandes municipios. Algunos Estatutos de Autonomía, introdujeron, por su parte, unas veces, referencias directas al fenómeno metropolitano (así, los artículos 5-2 $2^{\circ}$ del Estatuto catalán, 6-3 ${ }^{\circ}$ del asturiano, $3-2^{\circ}$ del murciano o $46-3^{\circ}$ del valenciano) y, otras, referencias indirectas, mediante la utilización de la expresión «agrupaciones basadas en hechos urbanísticos y otros de carácter funcional con fines específicos» (así, por ejemplo, el artículo 40-2 $2^{\circ}$ del Estatuto gallego $)^{14}$. En ningún caso, sin embargo, se contenía una regulación material mínima de las Áreas Metropolitanas ni, lo que hubiese sido más importante, una decisión sobre su papel

\footnotetext{
12 Publicado por la Revista de Administración Pública, 41, 1963, pp. 339 y ss. Comisión de la que formaron parte García de Enterría, De Fuentes, González PÉrez y Fernández-Villa.

13 Vid. Tomas-Ramón FernÁndeZ, cit. pp. 666-667.

${ }^{14}$ Cfr. las referencias concretas en Rodríguez Álvarez, cit., p. 113-114. Bassols Coma, cit., pp. 606607. Argullol Murgadas, cit., pp. 530-532.
} 
en el entramado de la organización territorial autonómica. Sea como fuere, habrá que esperar a la Ley 7/1985, de 2 de abril, de Bases del Régimen Local (LBRL), para que las Áreas Metropolitanas encuentren una mínima regulación general (artículo 43), con paralelo reconocimiento de la competencia autonómica en la materia.

El caso de Madrid apareció, desde el primer momento, como un caso singular. Una vez decidida su constitución como Comunidad Autónoma, de carácter innegablemente metropolitano ${ }^{15}$, la creación de un Área Metropolitana, que coincidiría con gran parte de su territorio, no parecía tener mucho sentido y podría producir indeseables solapamientos competenciales ${ }^{16}$. En todo caso, el artículo 76 de la actual Ley 2/2003, de 11 de marzo, de Administración Local de la Comunidad de Madrid ha posibilitado la creación de Áreas Metropolitanas «para le gestión de concretas obras y servicios» ${ }^{17}$. De otro lado, ha de tenerse en cuenta que el artículo 6 del Estatuto de Autonomía de la Comunidad Autónoma madrileña preveía la aprobación de una Ley estatal reguladora de un régimen especial de Madrid en función de su condición de capital del Estado (artículo 5 CE), cuyo exacto alcance fue discutido por algún autor ${ }^{18}$. El actual Proyecto de Ley de capitalidad y régimen especial de Madrid, en trámite de aprobación parlamentaria, contiene, como su propia denominación indica, una regulación conjunta o integrada de las dos características de Madrid, como capital del Estado y como gran ciudad, aunque, dada la naturaleza de dicho Proyecto, no se aborda la cuestión metropolitana.

La Corporación Metropolitana de Barcelona fue suprimida por la Ley catalana 7/1987, de 4 de abril, sustituyéndola por dos Entidades Metropolitanas de naturaleza sectorial y de extensión territorial diferente: la Entidad Metropolitana del Transporte y la Entidad Metropolitana de Servicios Hidráulicos y Tratamiento de Residuos. Es de subrayar que el hecho de esta supresión, con clara motivación política, no hizo que el resto de las funciones metropolitanas regresasen al nivel municipal, como pretendía la citada Ley, sino que la realidad misma de la conurbación propició la constitución, en 1988, de la Man-

${ }^{15}$ Por Orden de 16 de junio de 1983 los servicios de la COPLACO fueron trasferidos a la Comunidad de Madrid.

${ }^{16}$ Tomás-Ramón FeRNÁNDEZ ha afirmado que «Madrid constituye una región autónoma metropolitana, que encuentra en el vigente Estatuto de Autonomía de la Comunidad de Madrid una organización y una estructura de gobierno que satisface plenamente las exigencias inherentes al concepto de área metropolitana». «Madrid», en Le città metropolitane. Incontri di Diritto administrativo Italia-Spagna, Il Mulino, Bologna, 1994, p. 109.

${ }^{17}$ La Ley madrileña 3/2003, de 11 de marzo, para el desarrollo del pacto local, ha posibilitado la transferencia o delegación de competencias también a favor de las Entidades Locales de carácter supramunicipal (artículo $3-1^{\circ}$ ).

18 Vid. J. FERRET JACAS, «La legislación en materia de grandes ciudades y las competencias autonómicas», Informe Comunidades Autónomas 2002, Instituto de Derecho Público, Barcelona, pp. 606-607. El artículo $40-1^{\circ}$ de la Ley 2/2003, de 11 de marzo, de Administración Local de la Comunidad de Madrid contiene también, por su parte, la previsión de un régimen especial para Madrid en su condición de capital del Estado. 
comunidad de Municipios del Área Metropolitana de Barcelona con naturaleza plurifuncional ${ }^{19}$. Más aún la reciente Ley $1 / 2006$, de 13 de marzo, por la que se regula el Régimen Especial del Municipio de Barcelona en lo que se refiere a materias de competencia estatal ${ }^{20}$, alude ya, en su Disposición adicional segunda, a la futura creación del Área Metropolitana de Barcelona ${ }^{21}$.

La Ley valenciana 5/1986, de 19 de noviembre, extinguió, por su parte, la Corporación Administrativa Gran Valencia, atribuyendo sus competencias de planificación urbanística a los municipios, al mismo tiempo que creaba un instrumento de planeamiento nuevo, las Normas de Coordinación Metropolitana, que deberían se aprobadas por el Gobierno autonómico. Muy poco tiempo después, sin embargo, la Ley 12/1986, de 31 de diciembre, creó el llamado Consell Metropolità de l'Horta, un Área Metropolitana plurifuncional de competencias no muy claramente definidas, a la que no se le atribuyó le gestión de concretos servicios públicos ni se la dotó de efectivos instrumentos de coordinación de las actuaciones municipales en asuntos de interés metropolitano ${ }^{22}$. Precisamente con la finalidad de clarificar el ámbito de actuación y la organización del citado Consell, la Ley 4/1995, de 16 de marzo, creó el Área Metropolitana de l'Horta a la que asignó, inicialmente, la titularidad de las competencias sobre el servicio metropolitano del agua en alta, sobre el tratamiento y eliminación de residuos sólidos urbanos, sobre incendios y sobre mataderos, a la vez que diseñó una nueva estructura de sus órganos de gobierno. Poco duró la vida efectiva del Área Metropolitana, que fue suprimida por la Ley 8/1999, de 3 de diciembre, con el pretexto, según se decía en su Preámbulo, de que no había desarrollado todas las competencias ni la prestación de servicios supramunicipales para los que fue creada y de que era conveniente huir de estructuras administrativas rígidas y permanentes. Pues bien, a pesar de dicha declaración, la Ley 2/2000, de 23 de noviembre, creó la Entidad Pública de Transporte Metropolitano de Valencia y, sobre todo, la Ley 2/2001, de 11 de mayo, reguló, con carácter general, la constitución de Áreas Metropolitanas en toda la Comunidad Autónoma, a la vez que dispuso la creación de dos Entidades metropolitanas sectoriales: la Entidad Metropolitana de Servicios Hidráulicos y la Entidad Metropolitana para el Tratamiento de Residuos.

\footnotetext{
19 Vid. J. ToRnos MAS, «Las ciudades metropolitanas. El caso de Barcelona (nacimiento, desarrollo muerte y resurrección del Área Metropolitana de Barcelona)», Revista Aragonesa de Administración Pública, 3, 1993, pp. 11 y ss.

${ }^{20}$ En aplicación de lo dispuesto en la Disposición adicional sexta de la LBRL de 1985 (modificada por Ley 11/1999, de 21 de abril), el régimen especial del municipio de Barcelona está integrado por la citada Ley estatal 1/2006 y por la Ley catalana 22/1998, de 30 de diciembre, de la Carta Municipal de Barcelona.

${ }^{21}$ Cfr. la regulación general sobre las Entidades metropolitanas contenida en los artículos 94 a 96 del Texto Refundido de la Ley Municipal y de Régimen Local de Cataluña aprobado por Decreto Legislativo 2/2003, de 28 de abril.

22 Vid. J. M ${ }^{a}$ BAÑo LEÓN, «Valencia», en Le Città Metropolitane, cit., pp. 139 y ss., en concreto pp. $141-143,146-147$.
} 
Por lo que a Bilbao se refiere, ha de advertirse que la Ley vasca 3/1980, de 18 diciembre, suprimió la Corporación Administrativa del Gran Bilbao, sin que, por el momento, se haya procedido a la creación de un Área Metropolitana con este ámbito territorial. El tema es tributario, por lo demás, de una previa clarificación competencial, en este punto, entre los Territorios Históricos y la Comunidad Autónoma.

Ha de añadirse, por último, que la Ley estatal 53/2003, de 16 de diciembre, de medidas para la modernización del gobierno local, al regular el régimen organizativo de los allí denominados municipios de gran población, no abordó, quizás por razones de índole competencial, el tema metropolitano.

\section{LAS ÁREAS METROPOLITANAS EN LA LEGISLACIÓN BÁSICA ESTATAL}

Como ya se ha indicado, el fenómeno de las Áreas Metropolitanas ha encontrado expresa previsión en el artículo 43 de la citada Ley estatal 7/1985, de 2 de abril, reguladora de las Bases del Régimen Local (LBRL), en donde se las define como "Entidades locales integradas por los Municipios de grandes aglomeraciones urbanas entre cuyos núcleos de población existan vinculaciones económicas y sociales que hagan necesaria la planificación conjunta y la coordinación de determinados servicios y obras" ${ }^{23}$. En todo caso, y con independencia de esta definición legal, de la lectura conjunta de los distintos apartados del mencionado artículo 43 LBRL pueden ya deducirse dos características generales de la regulación básica estatal.

La primera característica sería la del fuerte grado de "interiorización" autonómica de la regulación del fenómeno de las Áreas Metropolitanas en la Ley Básica de 1985, tal como subrayaría, más tarde, el Tribunal Constitucional en su sentencia 214/1989, de 21 de diciembre. No se puede, por lo demás, descartar totalmente que la futura reforma de la actual Ley Básica estatal deje en manos de las Comunidades Autónomas la práctica totalidad de la temática de la supramunicipalidad ${ }^{24}$.

La segunda característica de la vigente regulación básica sería la de la posibilidad del establecimiento de un régimen jurídico diferenciado para cada Área Metropolitana. Régimen jurídico que podría venir previsto, previamente, en la correspondiente Ley autonómica de Régimen Local o en una Ley ge-

\footnotetext{
23 J. L. IBARRA RoBles, «El hecho metropolitano como ámbito territorial significativo y relevante para la reordenación de las estructuras locales», Autonomies, 5, 1986, pp. 118-119, observa que los orígenes de esta definición legal se encuentran en la Ley 41/1975.

${ }^{24}$ En el Libro Blanco para la reforma del gobierno local, MAP, Madrid, 2005, p. 72, se advertía, en todo caso, que el debate metropolitano es, en la actualidad, uno de de los grandes ejes de las políticas locales que requiere una atención prioritaria por parte de los poderes públicos.
} 
neral, también autonómica, sobre Áreas Metropolitanas, en el marco de las cuales habría de dictarse la Ley de creación de cada concreta Área Metropolitana. El problema que aquí se plantearía sería el de saber si esta última podría contener alguna regulación que se desviase de lo previsto en las Leyes generales. En este sentido, no me parece que exista inconveniente técnico alguno en afirmar que el legislador autonómico, a la hora de creación de una determinada Área metropolitana, goza de total libertad de configuración si cumple los requisitos expresamente establecidos en la normativa básica estatal (en la actualidad, el artículo 43 LBRL). Afirmar lo contrario sería otorgar a la Ley autonómica de Régimen Local o a la Ley autonómica sobre Áreas Metropolitanas una posición ordinamental que solo sería predicable de la normativa básica estatal en su relación con las normas autonómicas de desarrollo. En definitiva, las leyes singulares de creación de Áreas Metropolitanas podrían proceder a eventuales modificaciones de las leyes generales sobre la materia. Con independencia de que las Leyes autonómicas de Régimen Local o las Leyes generales sobre Áreas metropolitanas puedan contener las líneas generales del régimen jurídico de estas últimas, lo cierto es que solo a través de las concretas leyes singulares de creación se hace posible la variedad competencial y organizativa que puede derivarse del establecimiento de dichas Áreas.

La legislación básica estatal exige, en todo caso, para la creación de Áreas Metropolitanas, la concurrencia previa de unos requisitos o condiciones de carácter material y formal ${ }^{25}$. El requisito material viene identificado con la necesidad de la existencia de los presupuestos descritos en la citada definición legal del artículo 43-2 $2^{\circ}$ LBRL que traducen la existencia de verdaderos intereses metropolitanos. Naturalmente, en la constatación de dichos presupuestos, el legislador autonómico goza de un amplio margen de apreciación. La noción misma de «interés metropolitano» no deja de ser un concepto jurídico indeterminado que podría formar parte de una eventual cláusula general al diseñarse el ámbito competencial de las Áreas metropolitanas. En este sentido, si el legislador autonómico, en la creación de una determinada Área, optase por la inclusión de una cláusula general competencial al lado de las competencias atribuidas, aquella podría, en consecuencia, promover toda clase de actividades que contribuyesen a satisfacer los intereses metropolitanos, siempre, claro está, que dichas actividades no hubiesen sido expresamente atribuidas a la competencia de otras Administraciones públicas ${ }^{26}$.

Son varios los requisitos formales previstos en la Ley Básica de 1985 para la creación de Áreas Metropolitanas. El primero de todo ellos, al que ya he aludido anteriormente, es la reserva de ley (autonómica) en esta materia, con

\footnotetext{
${ }^{25}$ Cfr. M ${ }^{\text {a }}$ C. BARrero, «Las Áreas Metropolitanas», cit., pp. 211 y ss.

${ }^{26}$ R. Martín Mateo, «Las Áreas Metropolitanas», en Tratado de Derecho Municipal, I, (dirigido por S. Muñoz Machado), Civitas, Madrid, 1988, p. 857, ha escrito, en este sentido, que, con apoyo en nuestro Derecho actualmente vigente, hay base también para afirmar la vocación de absorción de las Áreas Metropolitanas de todas las obras y servicios que sean «de prestación o realización metropolitana».
} 
señalamiento de un contenido mínimo a la misma (artículo $43-1^{\circ}$ y $3^{\circ}$ LBRL). El segundo requisito formal viene constituido por la necesidad de previa audiencia de la Administración del Estado y de los Ayuntamientos y Diputaciones afectados. Se ha discutido en nuestra doctrina sobre el posible alcance que habría de adjudicarse a este trámite de audiencia, esto es, sobre el valor o grado de vinculación que del mismo se derivaría para el legislador autonómico. Pues bien, no creo que deba atribuirse a este trámite un valor vinculante que haría imposible la creación de un Área Metropolitana en el caso de un resultado negativo de tales audiencias. Ello afectaría a la libertad de configuración del legislador en materia de organización territorial. De otro lado, el carácter vinculante de tales audiencias tendría que haber sido previsto expresamente en la norma del artículo 43-1 ${ }^{\circ}$ LBRL y aún, si así hubiese sido, se plantearían problemas de orden constitucional ante lo que podría constituir un claro exceso de lo básico ${ }^{27}$. El tercer requisito formal, en fin, se refiere a la necesidad de que todos los municipios del Área estén representados en sus órganos de gobierno y a la garantía de la participación de todos ellos en la toma de decisiones. La Ley Básica estatal no ha establecido criterios concretos de representación, tarea que habrán de llevar a cabo las respectivas Leyes de creación de Áreas Metropolitanas (sistema proporcional a la población de cada municipio, sistema de voto ponderado en el funcionamiento del Área, etc.).

Quizás sea oportuno advertir que, a diferencia de lo dispuesto respecto de las comarcas, la Ley Básica estatal no contempla la iniciativa municipal para la creación de Áreas Metropolitanas por lo que habrá de estarse a lo que establezca al respecto la legislación autonómica. En este sentido, por ejemplo, el artículo $122-1^{\circ}$ de la Ley 5/1997, de 22 de julio, de Administración Local de Galicia (LALGA), dispone que «la iniciativa para la creación del área metropolitana podrá partir de los municipios interesados». Estamos, en este caso, ante una norma de carácter meramente potestativo que no podría condicionar la concreta delimitación del territorio metropolitano que, en su momento, llevase a cabo la Ley de creación de una determinada Área Metropolitana. En términos más generales, puede afirmarse que tampoco aquí la iniciativa municipal podría limitar la libertad de configuración de la organización territorial del espacio autonómico que el legislador ejerce a la hora de disponer la creación de un Área metropolitana en un ámbito territorial determinado. Por lo demás, sobre la relación entre la Ley de creación y la Ley autonómica de Régimen Local he tenido ya ocasión de pronunciarme antes.

La temática de la creación de las Áreas Metropolitanas comprende también, naturalmente, la cuestión de su naturaleza jurídica ${ }^{28}$. Nada dice la ac-

\footnotetext{
27 Sobre el valor de estas audiencias, vid. M ${ }^{\mathrm{a}}$ C. BARRERO, «Las Áreas Metropolitanas», cit., pp. $215-$ 217 y bibliografía allí citada.

${ }^{28}$ Cfr. $\mathrm{M}^{\mathrm{a}}$ C. BARRERo, «Las áreas metropolitanas», cit., pp. 65 y ss., especialmente pp. 71 y ss.; también, «Algunas reflexiones en torno a la naturaleza jurídica de las entidades supramunicipales», en $A d$ -
} 
tual LBRL sobre la naturaleza territorial o institucional de las Áreas metropolitanas que se limita simplemente a calificarlas de Entidades Locales (artículo 3-2 $2^{\circ}$, letra c). Será, pues, el legislador autonómico el que tendrá que llevar a cabo la configuración concreta de este tipo de Entidades Locales. Así, por ejemplo, el artículo 2 de la citada LALGA de 1997 ha optado por adjudicar a las Áreas Metropolitanas la condición de «Entidades locales no territoriales». En cualquier caso, convendría recordar, antes que nada, que la clásica distinción entre entes territoriales y no territoriales encuentra muchas dificultades cuando se aplica, precisamente, a los Entes locales ${ }^{29}$. En este sentido, el que el legislador autonómico califique a las Áreas Metropolitanas como Entes locales no territoriales, no quiere decir que pueden ser consideradas, sin más, como meros Entes instrumentales, gestores de los intereses de un Ente matriz. Ello sería incompatible con la efectiva existencia de verdaderos intereses metropolitanos (o, si se prefiere, de materias de indudable vocación metropolitana) y, por lo tanto, con lo que sería la verdadera naturaleza de las Areas Metropolitanas portadoras de dichos intereses, las cuales, por cierto, pueden proceder, por su parte, a la creación de sus propios Entes instrumentales como, de manera expresa, se prevé en la legislación autonómica (así, por ejemplo, en el artículo 125-1 $1^{\circ}$, letra g, de la LALGA). De otro lado, es muy significativo que la propia LBRL no haya limitado, de entrada, el alcance de la titularidad de las potestades administrativas de las Áreas Metropolitanas (artículo 4-2 ${ }^{\circ}$ ), que pueden, por consiguiente, ser las mismas que las propias de los Entes locales necesarios de carácter territorial, si así lo dispone el legislador autonómico ${ }^{30}$. Así ha ocurrido en la mayoría de los casos. La LALGA de 1997, sin embargo, excluyó, en concreto, a la potestad expropiatoria del conjunto de las potestades metropolitanas (artículo 6-2 $2^{\circ}$, letra b). Sin mucho fundamento, por cierto, ya que, en primer lugar, si la provincia, que tiene en común con las Áreas Metropolitanas el ser un Ente local de naturaleza asociativa, goza de la titularidad de la potestad expropiatoria, no se comprende muy bien porque estas últimas, que gestionan importantes intereses metropolitanos, se verían privadas de ella. En segundo lugar, si el más pequeño de los municipios, con una limitada capacidad de gestión, detenta la titularidad de la potestad expropiatoria, con mayor razón debería ser este el caso de las Áreas Metropolitanas, con un contenido competencial más extenso y una capacidad de gestión mucho mayor. No es, por tanto, adecuada, en mi opinión, la restricción operada por la LALGA en lo que se refiere a la titularidad de la potestad expropiatoria por parte de las Áreas metropolitanas. En todo caso, y como

\footnotetext{
ministración Institucional, libro homenaje a F. Clavero Arévalo, tomo I, Instituto García Oviedo-Civitas, Madrid, 1994, pp. 239 y ss., especialmente pp. 264 y ss.; «El juego de las Entidades supramunicipales en España. Algunas reflexiones en el décimo aniversario de la Ley de Régimen Local de 2 de abril de 1985», REALA, 264, 1994, pp. 627, especialmente pp. 655 y ss.

${ }^{29} \mathrm{Cfr}$. las reflexiones de A. FAnLo LoRAs, «Las prerrogativas locales», en Tratado de Derecho Municipal, I, cit., p. 506. M ${ }^{a}$ C. BARRERO, «Las Áreas Metropolitanas», cit., pp. 72 y ss., en especial p. 85.

${ }^{30}$ Vid. A. FANLO, «Las prerrogativas locales», cit., p. 505.
} 
ya se ha tenido ocasión de apuntar en estas páginas, la Ley de creación de un Área Metropolitana le podría otorgar, derogando en este punto a la citada LALGA, la titularidad de la potestad expropiatoria, a la vez, por cierto, que le podría también adjudicar, expresamente, la naturaleza de verdadero Ente local de naturaleza territorial.

Por último, y desde otra perspectiva, las Áreas Metropolitanas también podrían encontrar en los textos estatutarios, actualmente en proceso de reforma, una cierta garantía de su autonomía que se tradujese en la necesidad de que el legislador autonómico estructurase su ámbito competencial con base en verdaderas competencias propias y no simplemente delegadas. Esta cuestión nos lleva ya a alguna reflexión, también muy sucinta, sobre las competencias metropolitanas.

\section{LAS COMPETENCIAS METROPOLITANAS. La posibilidad de una cláusula general competencial. Carác- ter propio de las competencias. Ámbito competencial metro- politano y autonomía municipal. Una descripción general del ámbito competencial metropolitano. Una cuestión importan- te: ámbito competencial provincial y territorio metropolitano}

Toda reflexión sobre las competencias metropolitanas debe partir, como no podría ser de otra manera, de su necesaria vinculación a los intereses propios del espacio metropolitano, como se deduce, por lo demás, de los apartados segundo y tercero del artículo 43 LBRL. Ya sabemos que corresponderá al legislador autonómico la concreta identificación, en cada caso, de esos intereses metropolitanos. Ello permite también la adopción de distintos modelos competenciales según las características de cada Área Metropolitana, modelos que pueden prever, además, una asunción paulatina de las correspondientes competencias, si se considerase conveniente para una puesta en marcha más eficaz de la actividad de aquella.

Ha quedado ya apuntado que nada impide que el modelo competencial metropolitano pueda contener una cláusula general que permita, también a las Áreas Metropolitanas, el ejercicio de un «derecho a la espontaneidad» en el desarrollo de sus actividades. En todo caso, una mejor organización del espacio metropolitano exigiría un modelo competencial montado sobre un sistema de competencias atribuidas como propias y no como meramente delegadas $^{31}$, lo cual sería más coherente con los intereses que les sirven de base y, por derivación, con una eventual consagración estatutaria de la autonomía de los Entes metropolitanos.

\footnotetext{
31 Vid. R. GómEZ-FERRER, «Encaje constitucional de la Administración metropolitana», Documentación Administrativa, 182, 1979, p. 403. M ${ }^{\text {a }}$ C. BARRERO, «Las Áreas Metropolitanas», cit., pp. 131-132, 134136.
} 
La determinación del ámbito metropolitano de actuación encuentra en la autonomía municipal un condicionamiento esencial. Como se advertía en la emblemática STC 214/1989, de 21 de diciembre, la creación de un Área Metropolitana no puede afectar al contenido competencial mínimo de los municipios que la integran. En el mismo sentido, el artículo 121-3 ${ }^{\circ}$ LALGA dispuso que «en ningún caso la creación de un área metropolitana puede suponer la pérdida de competencias de los municipios integrados que les hagan perder su condición de tales $»^{32}$. Hay que tener en cuenta, con todo, que la misma LBRL (artículo 26- $1^{\circ}$ ) permite que las competencias municipales mínimas de ejercicio obligatorio pueden también ser ejercidas de forma asociada. Alternativa que, por ejemplo, fue recordada por nuestro Tribunal Supremo con motivo del acuerdo de asunción de la titularidad de los servicios de transporte urbano de viajeros por la desaparecida Entidad Metropolitana de Barcelona (sentencia de 3 de julio de 1990). De otro lado, conviene recordar también que los propios municipios pueden solicitar de su Comunidad Autónoma la dispensa de la obligación de prestar los servicios mínimos que les correspondan (artículo 26-2 ${ }^{\circ}$ LBRL).

La garantía de la representación de los municipios en los órganos de gobierno metropolitanos, así como el aseguramiento de su participación efectiva en la toma de decisiones, permite concluir que, en este caso, los municipios no pierden su condición de tales (por utilizar la misma expresión de la Ley gallega), sino que ejercen muchas de sus competencias, incluidas, en su caso, las de ejercicio obligatorio, a través del procedimiento de decisión propio de las Áreas Metropolitanas. El interés municipal se vería así integrado en el seno del interés metropolitano. Por lo demás, la creación del Área Metropolitana puede ser, incluso, el medio más adecuado para evitar la pérdida del carácter local de muchos asuntos, lo que provocaría su inevitable desplazamiento al nivel autonómico y, en algunos casos, al estatal.

En lo que a una descripción general del posible ámbito metropolitano de actuación se refiere, puede decirse que, en el marco de la correspondiente legislación autonómica, este suele traducirse en competencias de planificación (en materia de ordenación territorial y urbanística metropolitana, en materia de planificación comercial de ámbito supramunicipal o en materia de planificación de infraestructuras viarias) y en competencias de gestión de servicios públicos metropolitanos (abastecimiento de agua potable y depuración de aguas residuales, transporte de viajeros, residuos urbanos, protección civil, servicios sociales de atención especializada, etc.). A todo ello puede añadirse la posibilidad de atribución a los Entes metropolitanos de determinadas competencias de fomento en materia económica y social o en materia cultural y turística.

\footnotetext{
${ }^{32}$ Por su parte el artículo $133-1^{\circ}$ estableció que «el objeto del área metropolitana será determinado y no podrá incluir todas las competencias de los municipios que la integren».
} 
En materia de seguridad ciudadana ha de tenerse en cuenta que la jurisprudencia constitucional dictada en relación con una serie de Leyes autonómicas de coordinación de las policías locales advirtió sobre la imposibilidad legal de creación de cuerpos de policía supramunicipales o, incluso, de la prestación asociada o en común del servicio policial ${ }^{33}$. Queda abierta, según esta misma jurisprudencia, la posibilidad de adscripción temporal de agentes de policía de un municipio a otro mediante las correspondientes comisiones de servicio (STC 86/1993, de 8 de marzo, FJ $3^{\circ}$, referida al caso de la Comunidad Autónoma de Galicia), posibilidad que podría quedar plasmada en un convenio de colaboración suscrito por los municipios integrantes del Área Metropolitana.

Para un ejercicio coordinado de sus competencias las Áreas Metropolitanas habrán de elaborar un Plan de actuación, de vigencia plurianual, en el que, necesariamente, deberían tenerse en cuenta la solidaridad y el equilibrio intermunicipales.

En lo que se refiere a la prestación de los servicios públicos metropolitanos, el Área Metropolitana tiene a su disposición cualquiera de las formas de gestión previstas en el Ordenamiento local, debiéndose optar, naturalmente, por aquella que contribuya a una mayor calidad y eficacia de dicha prestación. De otro lado, nada impide que el Área Metropolitana pueda ejercer la iniciativa pública en la actividad económica en los términos establecidos constitucional y legalmente.

El ámbito competencial metropolitano podrá verse ampliado a través de las eventuales transferencias o delegaciones que puedan llevar a cabo las Administraciones estatal, autonómica o provincial. Incluso la Administración autonómica en concreto podría, de otro lado, encomendar al Área Metropolitana la gestión ordinaria de sus servicios propios en el territorio metropolitano, en los términos previstos en el Ordenamiento local.

Un tema importante que merecería un análisis detenido es el de las consecuencias competenciales que para la correspondiente provincia conllevaría la creación de un Área Metropolitana. Lo que habría de evitarse serían los solapamientos competenciales que inevitablemente se producirían entre las dos Entidades, provincial y metropolitana, al participar ambas de la condición de ser agrupaciones de municipios que actúan sobre un mismo territorio. Esta es una problemática surgida ya en el inicio mismo de la regulación del fenómeno metropolitano ${ }^{34}$ y que ha adquirido una particular importancia en el actual Estado autonómico a la hora de abordarse la estruc-

\footnotetext{
33 Vid. E. Orduña Prada, «Las Áreas Metropolitanas», cit., pp. 106-109 y nota 32, donde se contiene la enumeración de las sentencias del TC en la materia.

${ }^{34}$ Cfr. Informe y Anteproyecto de la Ley sobre el Área Metropolitana de Madrid, cit., p. 344. T. R. FERNÁNDEZ, «Áreas metropolitanas y Descentralización», cit., pp. 712 y ss. «Madrid», en Le Città Metropolitane, cit., p. 104.
} 
turación interna, competencial y organizativa, de las Comunidades Autónomas $^{35}$. Habrá, pues, que plantearse necesariamente, en un momento de profunda renovación del marco estatutario, la importante cuestión de si las Áreas Metropolitanas no podrían ejercer, en su ámbito territorial, y a través de las correspondientes técnicas de coordinación, de asignación o de delegación competencial, las mismas funciones que hasta este momento venían desempeñando, en dicho ámbito, las Diputaciones Provinciales, las cuales, por consiguiente, concentrarían su actividad en el resto de los municipios, situados fuera del territorio metropolitano y caracterizados por su pequeña dimensión. Esta operación de redistribución competencial, consecuencia inevitable del ejercicio de la competencia autonómica de creación de otras Entidades locales (STC 214/1989, de 21 de diciembre, FJ $4^{\circ}$ ), no afectaría, en mi opinión, al contenido esencial de la garantía institucional de la provincia (cifrado, concretamente, por la STC 109/1998, de 21 de mayo, en la actuación de cooperación con los municipios), pues no produciría su total vaciamiento competencial, incompatible con dicha garantía. Entre otras razones, y en primer lugar, porque las Diputaciones provinciales, como se acaba de apuntar, seguirían manteniendo importantes competencias directas sobre los pequeños municipios, no comprendidos en el espacio metropolitano y, en segundo lugar, porque el contenido de la autonomía provincial se manifiesta en competencias de naturaleza instrumental que pueden ser desarrolladas también, coordinada y paralelamente, en su respectivo ámbito, por las Áreas Metropolitanas. En aras a una estructuración más eficaz de la organización autonómica interna, la delimitación de los ámbitos de actuación de Áreas Metropolitanas y Diputaciones, en el seno del territorio metropolitano, podría encontrar en la eventual creación de una Comisión de Coordinación, de la que, por cierto, no debería estar ausente el Gobierno autonómico, la vía más conveniente para su realización. En definitiva, la asunción de las tareas de las Diputaciones por las Áreas Metropolitanas, en su propio territorio, produciría un proceso de simplificación administrativa que evitaría una reduplicación, orgánica y competencial, absolutamente indeseable en el espacio metropolitano.

\footnotetext{
${ }^{35}$ Cfr. R. Gómez-Ferrer, «Encaje constitucional de la Administración metropolitana», cit., p. 407. M ${ }^{\mathrm{a}}$ C. BARrero, «Las Áreas Metropolitanas», cit., pp. 117 y ss., en especial, pp. 132-134; «Algunas reflexiones», cit., pp. 271-274. E. Orduña PradA, «Las Áreas Metropolitanas», cit., p. 116. J. ToRnOS MAS, «Elementos para la reorganización territorial de Cataluña», AGL 1999/2000, p. 181. E. ARGULLOL, «Las opciones de organización territorial de Cataluña», REALA, 223, 1984, pp. 307 y ss. J. L. IbARRa Robles, «Problemática actual de las Áreas Metropolitanas en España», en El Espacio Metropolitano, cit., p. 42; «El hecho metropolitano», cit., p. 121.
} 